\title{
Bg/ll gene polymorphism of the $\alpha 2 \beta 1$ integrin gene is a risk factor for diabetic retinopathy in Caucasians with type 2 diabetes
}

Received: 13 May 2003/ Accepted: 8 July 2003/Published online: 23 August 2003

(C) The Japan Society of Human Genetics and Springer-Verlag 2003

\begin{abstract}
Platelets are thought to be involved in the pathogenesis of diabetic retinopathy. The BglII gene polymorphism of the $\alpha 2 \beta 1$ integrin, which is a platelet collagen receptor, has been suggested as a genetic risk factor for diabetic retinopathy in Japanese subjects. The aim of this study was to look for a relationship between the $B g / I I$ gene polymorphism of the $\alpha 2 \beta 1$ integrin gene and the development of diabetic retinopathy in Caucasians with type 2 diabetes. Subjects with type 2 diabetes and diabetic retinopathy $(n=163)$ were compared with diabetic subjects without diabetic retinopathy $(n=95)$. A significantly higher frequency of the BglII $(+/+)$ genotype of the gene polymorphism of the $\alpha 2 \beta 1$ integrin gene was found in patients with diabetic retinopathy compared with patients without diabetic retinopathy $(19.6 \%$ vs $7.4 \% ; P=0.008)$. The present study demonstrates that the $B g / \mathrm{II}(+/+)$ genotype of the gene polymorphism of the $\alpha 2 \beta 1$ integrin gene is an independent risk factor (odds ratio: $2.4,95 \%$ confidence interval $1.0-6.0 ; P<0.05)$ for diabetic retinopathy in Caucasians with type 2 diabetes.
\end{abstract}

Keywords $B g /$ II gene polymorphism of the $\alpha 2 \beta 1$ integrin · Diabetic retinopathy · Type 2 diabetes . Association study $\cdot$ Genetic risk factor

M. G. Petrovič · M. Hawlina

Eye Clinic, University Medical Centre Ljubljana, Ljubljana, Slovenia

B. Peterlin

Division of Medical Genetics,

Department of Obstetrics and Gynecology,

University Medical Centre Ljubljana,

Ljubljana, Slovenia

D. Petrovič $(\bowtie)$

Institute of Histology and Embryology,

Medical Faculty, University of Ljubljana,

Korytkova 2, SI-1000 Ljubljana, Slovenia

E-mail: daniel.petrovic@mf.uni-lj.si

Tel.: + 386-1-5437367

Fax: + 386-1-5437361

\section{Introduction}

Diabetic retinopathy, a leading cause of blindness in the working population, is a microvascular complication of diabetes (Klein and Klein 1995). Several epidemiological and experimental studies indicate that the duration of diabetes and glycemic control are major determinants for the development of diabetic retinopathy, whereas previously identified nongenetic risk factors are variable and include $\mathrm{HbA}_{1 \mathrm{C}}$, age at diagnosis, blood pressure, plasma cholesterol, proteinuria, fasting glycemia, body mass index (BMI), waist-to-hip ratio, and insulin treatment (Engerma and Kern 1987; Porta et al. 2001; Keen et al. 2001). Diabetic retinopathy is characterized by increased vascular permeability, hemostatic abnormalities, increased tissue ischemia, and neoangiogenesis (Winocour 1992). Platelets are thought to be involved in the pathogenesis of diabetic retinopathy (Barnett 1991). Platelets from diabetic patients are hyper-reactive to aggregating agents, such as collagen, thrombin, and adenosine diphosphate (Winocour 1992). The platelet membrane glycoprotein Ia/IIa, $\alpha 2 \beta 1$ integrin, serves as a platelet receptor for collagen (Santoro and Zutter 2001; Moroi and Jung 1997). Recently, genetic variations in $\alpha 2 \beta 1$ integrin have been shown to affect the density of $\alpha 2 \beta 1$ receptors on the platelet surface (Kritzik et al. 1998; Kunicki et al. 1997). Moreover, Matsubara et al. (2000) have demonstrated the association between genetic variations in $\alpha 2 \beta 1$ integrin and diabetic retinopathy in the Japanese population. The aim of this study has been to determine whether the $B g / I I$ gene polymorphism of the $\alpha 2 \beta 1$ integrin gene is a risk factor for the development of diabetic retinopathy in Caucasians with type 2 diabetes.

\section{Patients and methods}

In this cross-sectional case-control study, 258 unrelated Caucasian subjects were enrolled with type 2 diabetes mellitus with a defined ophthalmologic status. Standard World Health Organization criteria were used for the diagnosis of diabetes mellitus (WHO 1985). 
Subjects were recruited from the Eye Clinic and from the Diabetic Outpatient Clinic of the University Medical Centre in Ljubljana. The staging of diabetic retinopathy was performed by a senior ophthalmologist (M.P.) after pupil dilation (tropicamide and phenylephrine $2.5 \%$ ) by using direct ophthalmoscopy and was electronically documented with a $50^{\circ}$ angle fundus camera (Topcon-TRC 40-IX, Tokyo, Japan). The study group consisted of 163 patients with diabetic retinopathy: 106 subjects with proliferative diabetic retinopathy (new vessel formation and/or fibrous proliferation) and 57 subjects with non-proliferative diabetic retinopathy (microaneurysms, retinal hemorrhages, hard exudates; Early Treatment Diabetic Retinopathy Study Research Group 1991). The control group consisted of 95 subjects with type 2 diabetes of duration of more than 10 years but no clinical signs of diabetic retinopathy.

To avoid the confounding effect of impaired kidney function, patients with overt nephropathy were not enrolled.

The study was approved by the National Medical Ethics Committee. A detailed interview was carried out once informed consent had been obtained from all participants in the study.

Arterial hypertension was defined as systolic blood pressure higher than $140 \mathrm{~mm} \mathrm{Hg}$ and diastolic blood pressure higher than $90 \mathrm{~mm} \mathrm{Hg}$, or both, at repeated measurements, or the current use of antihypertensive agents for confirmed diagnosis of arterial hypertension.

Total cholesterol, low-density lipoprotein (LDL), high-density lipoprotein (HDL), and triglycerides were determined by standard biochemical methods.

The characteristics of the patients and control subjects are listed in Table 1. The groups were matched for most clinical parameters except for the age and insulin treatment (Table 1).

The $B g / I I$ gene polymorphism of the $\alpha 2 \beta 1$ integrin gene was evaluated as described previously (Matsubara et al. 2000). Genotyping was performed by two researchers (D.P., B.P.), blinded to the retinopathy status of the patients.

Differences in mean values were assessed by the unpaired Student $t$ test and presented as means \pm standard deviation (SD). The chi-square test was used to compare discrete variables. Statistical analysis was performed by using the SPSS program for Windows version 11 (SPSS, Illinois). Statistical significance was set at $P<0.05$. Logistic regression analysis was performed to assess the independent role of the $B g / \mathrm{II}(+/+)$ genotype of the $\alpha 2 \beta 1$ integrin gene polymorphism and other variables, including age, age of onset of diabetes, duration of diabetes, and insulin therapy (categorical variable: insulin therapy or no therapy).

\section{Results}

The $B g l$ II $\alpha 2 \beta 1$ integrin genotype distribution in cases and controls was compatible with Hardy-Weinberg expectations (cases $\chi^{2}=0.74, P=0.39$; controls $\chi^{2}=3.01$, $P=0.08)$. The characteristics of cases and controls are listed in Table 1. The frequencies of the genotypes of the $B g /$ II gene polymorphism of the $\alpha 2 \beta 1$ integrin gene are shown in Table 2; a significantly higher frequency of the $B g l$ II $(+/+)$ genotype was found in patients with diabetic retinopathy compared with subjects without diabetic retinopathy, with an odds ratio (OR) of 3.1 and a $95 \%$ confidence interval $(\mathrm{CI})$ of $1.3-7.3 ; P=0.008)$.

In the multivariate model (age, $B g$ lII $+/+$ genotype, insulin therapy, age of onset of diabetes, duration of diabetes), $B g l$ II $(+/+)$ genotype and insulin therapy were independent risk factors for diabetic retinopathy (Table 3).

\section{Discussion}

We are the first to provide evidence by case-control association study and logistic regression analysis that the $B g l$ II $(+/+)$ genotype of the BglII gene polymorphism of the $\alpha 2 \beta 1$ integrin gene is associated with an increased risk of diabetic retinopathy in a group of Caucasians with type 2 diabetes. This finding suggests that the $B g / I I$ gene polymorphism of the $\alpha 2 \beta 1$ integrin gene may contribute to genetic susceptibility to diabetic retinopathy in Caucasians with type 2 diabetes. Our finding is consistent with the results of the study reported by Matsubara et al. (2000) who have shown an association between genetic variations in $\alpha 2 \beta 1$ integrin and diabetic retinopathy in the Japanese population with type 2 diabetes. Moreover, Matsubara et al. (2000) have demonstrated an association between genetic variations in $\alpha 2 \beta 1$ integrin and diabetic nephropathy, another microvascular complication of diabetes, whereas Tsai et al. (2001) have failed to find such an association with diabetic nephropathy in the Chinese population with type 2 diabetes.

Recently, platelet $\alpha 2 \beta 1$ density, which has an important impact on platelet adhesion to collagens, has been shown to be genetically determined (Kritzik et al. 1998; Kunicki et al. 1997). An association between genetic
Table 1 Characteristics of patients with diabetic retinopathy $(D R)$ and patients without DR

\begin{tabular}{lccc}
\hline Characteristic & Subjects with DR & Subjects without DR & $P$ \\
\hline Number & 163 & 95 & \\
Age (years) & $66.1 \pm 9.4$ & $70.4 \pm 9.2$ & 0.001 \\
Male sex (\%) & $75(46.0)$ & $39(41.1)$ & 0.4 \\
Duration of diabetes (years) & $19.4 \pm 8.8$ & $17.0 \pm 6.9$ & 0.02 \\
Insulin therapy & $114(69.9)$ & $45(47.4)$ & $<0.001$ \\
Age of onset of diabetes & $46.5 \pm 10.9$ & $53.3 \pm 11.5$ & $<.001$ \\
HbA 1 (\%) & $8.5 \pm 1.8$ & $8.1 \pm 1.5$ & 0.6 \\
Systolic blood pressure (mm Hg) & $144 \pm 25$ & $146 \pm 20$ & 0.5 \\
Diastolic blood pressure (mm Hg) & $86 \pm 10$ & $84 \pm 8$ & 0.1 \\
BMI (kg/m ${ }^{2}$ ) & $27.8 \pm 4.5$ & $27.7 \pm 4.4$ & 0.9 \\
History of hypertension (\%) & $113(69.3)$ & $68(71.6)$ & 0.8 \\
Smokers (\%) & $24(14.7)$ & $12(12.6)$ & 0.6 \\
Total cholesterol (mmol/l) & $5.2 \pm 1.2$ & $5.5 \pm 1.2$ & 0.08 \\
HDL cholesterol (mmol/l) & $1.2 \pm 0.4$ & $1.2 \pm 0.6$ & 0.6 \\
LDL cholesterol (mmol/l) & $3.1 \pm 1.0$ & $3.3 \pm 0.9$ & 0.1 \\
Triglycerides (mmol/l) & $2.3 \pm 1.4$ & $2.6 \pm 2.0$ & 0.2 \\
\hline
\end{tabular}


Table 2 Integrin gene polymorphisms in patients with diabetic retinopathy $(D R)$ and in patients without DR

\begin{tabular}{|c|c|c|c|c|}
\hline & Patients with DR & Patients without DR & $\mathrm{P}$ & OR $(95 \% \mathrm{CI})^{\mathrm{a}}$ \\
\hline \multicolumn{5}{|l|}{ BglII polymorphism } \\
\hline BglII $(+/+)$ genotype & $32(19.6)$ & $7(7.4)$ & $0.01^{\mathrm{b}}$ & \\
\hline$B g l$ II $(+/-)$ genotype & $87(53.4)$ & $50(52.6)$ & & \\
\hline BglII $(-/-)$ genotype & $44(27.0)$ & $38(40.0)$ & & \\
\hline BglII $(+/+)$ genotype & $32(19.6)$ & $7(7.4)$ & $0.008^{\mathrm{c}}$ & $3.1(1.3-7.3)^{\mathrm{c}}$ \\
\hline BglII $(+/-)$ genotype + Bgl II $(-/-)$ genotype & $131(80.4)$ & $88(82.6)$ & & \\
\hline BglII $(+/+)$ genotype + Bgl II $(+/-)$ genotype & $119(73.0)$ & $57(60)$ & $0.03^{\mathrm{d}}$ & $1.8(1.0-3.1)^{\mathrm{d}}$ \\
\hline BglII $(-/-)$ genotype & $44(27.0)$ & $38(40.0)$ & & \\
\hline$B g l \mathrm{II}+$ allele & $151(0.46)$ & $64(0.34)$ & $0.005^{\mathrm{e}}$ & \\
\hline BglII -allele & $175(0.54)$ & $126(0.66)$ & & \\
\hline
\end{tabular}

${ }^{a}$ Odds ratio $(95 \%$ confidence interval)

${ }^{\mathrm{b}} P$ value for genotype frequency $(2 \times 3)=0.01$

${ }^{\mathrm{c}} P$-value and OR for recessive model $(B g / \mathrm{II}+/+$ versus $B g / \mathrm{II}+/-$ plus $B g / \mathrm{II}-/-)$

${ }^{\mathrm{d}} P$-value and OR for dominant model $(B g / \mathrm{II}+/+$ plus $B g l \mathrm{II}+/-$ versus $B g l \mathrm{II}-/-)$

${ }^{\mathrm{e}} P$ value for allele frequency

Table 3 Adjusted odds ratios $(O R)$ for risk factors for diabetic retinopathy (CI confidence interval)

\begin{tabular}{llc}
\hline Risk factors & OR $(95 \%$ CI $)$ & $P$ \\
\hline BglII $(+/+)$ genotype & $2.4(1.0-6.0)$ & $<0.05$ \\
Insulin therapy & $1.8(1.0-3.3)$ & $<0.05$ \\
Age of onset of diabetes & $1.8(0.5-5.7)$ & 0.3 \\
Duration of diabetes & $1.7(0.5-5.4)$ & 0.4 \\
Age & $0.6(0.2-1.9)$ & 0.4 \\
\hline
\end{tabular}

variations in $\alpha 2 \beta 1$ and the density of $\alpha 2 \beta 1$ receptors on the platelet surface has also been revealed (Kritzik et al. 1998; Kunicki et al. 1997). Moreover, Kunicki et al. (1997) have demonstrated that the density of $\alpha 2 \beta 1$ receptors on the platelet surface affects platelet adhesion to collagen, contributing to an increased risk of thrombosis. Alteration in retinal and renal blood flow, metabolic changes, hemostatic abnormalities, nonenzymatic glycosylation of collagen, and other tissue proteins are observed during long-term hyperglycemia (Winocour 1992; Patel et al. 1992; Koya et al. 1997). Platelets from diabetic patients may interact with exposed subendothelial fibrillar collagens, major components of the subendothelial matrix. Moreover, the amount of nonenzymatically glycosylated collagen, which is prone to interact with platelets, has recently been shown to be higher in diabetic patients than in nondiabetic controls (Kritzik et al. 1998; Kunicki et al. 1997). Platelets, activated by contact with collagens can trigger thrombus formation and small vessel occlusion (Winocour 1992).

Our results increase the knowledge of genetic risk factors for developing diabetic retinopathy in type 2 diabetes. Furthermore, our study and that reported by Matsubara et al. (2000) provide further evidence that platelets are involved in the pathogenesis of diabetic retinopathy. Moreover, our study demonstrates that insulin therapy is independent of the Bg/II gene polymorphism, which is statistically significantly associated with diabetic retinopathy. This finding suggests the existence of other factors, such as differences in the ability of insulin secretion, or differences in the frequency of episodes of hypoglycemia, or adverse events associated with insulin therapy (hypoglycemia, worsening diabetic retinopathy if $\mathrm{HbA}_{1 \mathrm{c}}$ decreases rapidly; DeWitt and Hirsch 2003; Dahl-Jorgensen et al. 1985).

In conclusion, we suggest that the $B g / I I$ gene polymorphism of the $\alpha 2 \beta 1$ integrin gene can be considered as a risk factor for diabetic retinopathy in Caucasians with type 2 diabetes.

Acknowledgements The authors thank Ms. Mojca Pirc BA for revising the English, Dejan Bregar for excellent technical assistance, and Ministry of Education, Science and Sport for financial support (national grants L3-2119-0381 and J3-8931-0312).

\section{References}

Barnett AH (1991) Pathogenesis of diabetic microangiopathy: an overview. Am J Med 90:67S-73S

Dahl-Jorgensen K, Brinchmann-Hansen O, Hanssen KF, Sandvik L, Aagenaes O (1985) Rapid tightening of blood glucose control leads to transient deterioration of retinopathy in insulin dependent diabetes mellitus: the Oslo study. BMJ 290:811-815

DeWitt DE, Hirsch IB (2003) Outpatient insulin therapy in type 1 and type 2 diabetes mellitus: scientific review. JAMA 289:2254-2264

Early Treatment Diabetic Retinopathy Study Research Group (1991) Grading diabetic retinopathy from stereoscopic color fundus photographs - an extension of the modified Airlie House classification. ETDRS report no. 10. Ophthalmology 98 (Suppl 5):786-806

Engerman RL, Kern TS (1987) Progression of incipient diabetic retinopathy during good glycemic control. Diabetes 36:808-812

Keen H, Lee ET, Russell D, Miki E, Bennett PH, Lu M (2001) The appearance of retinopathy and progression to proliferative retinopathy: the WHO Multinational Study of Vascular Disease in Diabetes. Diabetologia 44 (Suppl 2):S22-S30

Klein R, Klein BEK (1995) Visual disorders in diabetes: diabetes in America. In: Harris CI, Cowie CC, Stern MP, Boyko EJ, Reiber GE, Bennett PH (eds) Report of National Institutes of Diabetes and Digestive and Kidney Diseases. National Institutes of Health, Bethesda, pp 293-338

Koya D, Jirousek MR, Lin YW, Ishii H, Kuboki K, King GL (1997) Characterization of protein kinase C beta isoform activation on the gene expression of transforming growth factorbeta, extracellular matrix components, and prostanoids in the glomeruli of diabetic rats. J Clin Invest 100:115-126 
Kritzik M, Savage B, Nugent DJ, Santoso S, Ruggeri ZM, Kunicki TJ (1998) Nucleotide polymorphisms in the $\alpha 2$ gene define multiple alleles that are associated with differences in platelet alpha2 beta1 density. Blood 92:2382-2388

Kunicki TJ, Kritzik M, Annis DS, Nugent DJ (1997) Hereditary variation in platelet integrin $\alpha 2 \beta 1$ density is associated with two silent polymorphisms in the alpha 2 gene coding sequence. Blood 89:1939-1943

Matsubara Y, Murata M, Maruyama T, Handa M, Yamagata N, Watanabe G, Saruta T, Ikeda Y (2000) Association between diabetic retinopathy and genetic variations in $\alpha 2 \beta 1$ integrin, a platelet receptor for collagen. Blood 95:15601564

Moroi M, Jung SM (1997) Platelet receptors for collagen. Thromb Haemost 78:439-444

Patel V, Rassam S, Newsom R, Wiek J, Kohner E (1992) Retinal blood flow in diabetic retinopathy. BMJ 305:678-683
Porta M, Sjoelie AK, Chaturvedi N, Stevens L, Rottiers R, Veglio M, Fuller JH, EURODIAB Prospective Complications Study Group (2001) Risk factors for progression to proliferative diabetic retinopathy in the EURODIAB Prospective Complications Study. Diabetologia 44:2203-2209

Santoro SA, Zutter MM (2001) The $\alpha 2 \beta 1$ integrin: a collagen receptor on platelets and other cells. Thromb Haemost 74:813821

Tsai DH, Jiang YD, Wu KD, Tai TY, Chuang LM (2001) Platelet collagen receptor $\alpha 2 \beta 1$ integrin and glycoprotein IIIa $\mathrm{Pl}(\mathrm{A} 1 / \mathrm{A} 2)$ polymorphisms are not associated with nephropathy in type 2 diabetes. Am J Kidney Dis 38:1185-1190

Winocour PD (1992) Platelet abnormalities in diabetes mellitus. Diabetes 41 (Suppl 2):26-31

World Health Organization (1985) Diabetes mellitus: report of a WHO study group. WHO Technical Report Seris no. 727, pp 9-10 